\title{
EVALUATION OF ANTIFUNGAL ACTIVITY IN ESSENTIAL OIL OF THE SYZYGIUM AROMATICUM (L.) BY EXTRACTION, PURIFICATION AND ANALYSIS OF ITS MAIN COMPONENT EUGENOL
}

\author{
Inder Singh Rana*, Aarti Singh Rana, Ram Charan Rajak
}

Research \& Development Center, Kilpest India Ltd., Govindpura, Bhopal-462023, India.

Submitted: March 29, 2010; Returned to authors for corrections: August 23, 2010; Approved: May 30, 2011.

\begin{abstract}
Antifungal properties of some essential oils have been well documented. Clove oil is reported to have strong antifungal activity against many fungal species. In this study we have evaluated antifungal potential of essential oil of Syzygium aromaticum (L.) against some common fungal pathogens of plants and animals namely, Fusarium moniliforme NCIM 1100, Fusarium oxysporum MTCC 284, Aspergillus sp., Mucor sp., Trichophyton rubrum and Microsporum gypseum. All fungal species were found to be inhibited by the oil when tested through agar well diffusion method. Minimum inhibitory concentration (MIC) was determined for all the species. Column chromatography was performed to separate the eugenol rich fraction from clove oil. Out of seven fractions maximum activity was obtained in column fraction II. TLC and HPLC data confirmed presence of considerable Eugenol in fraction II and clove oil. Microscopic study on effect of clove oil and column fraction II on spores of Mucor sp. and M. gypseum showed distortion and shrinkage while it was absent in other column fractions. So it can be concluded that the antifungal action of clove oil is due to its high eugenol content.
\end{abstract}

Key words: Essential oil, Syzygium aromaticum, Antifungal, Chromatography, Eugenol

\section{INTRODUCTION}

In the past few decades, a worldwide increase in the incidence of fungal infections has been observed as well as a rise in the resistance of some species of fungus to different fungicides in medicine and agriculture. The last two decades have witnessed a dramatic rise in the incidence of life threatening systemic fungal infections. The majority of clinically used antifungals have various drawbacks in terms of toxicity, efficacy and cost, and their frequent use has led to the emergence of resistant strains. Additionally, in recent years public pressure to reduce the use of synthetic fungicides in agriculture has increased. Concerns have been raised about both the environmental impact and the potential health risk related to the use of these compounds (1).

The use of plant derived products as diseases control agents have been studied, since they tend to have low mammalian toxicity, less environmental effects and wide public acceptance (5).

Essential oils have a long history of use as natural microbial agents and have recently been used in a number of pharmaceutical, food, and cosmetic products since these oils effectively inhibit the growth of a wide range of microorganisms, with fewer side effects than synthetic

*Corresponding Author. Mailing address: Research \& Development Center, Kilpest India Ltd., Govindpura, Bhopal-462023, India.; Tel.: 91 9893573161.; Email: ranaindersingh@yahoo.com 
antimicrobial agents in humans. Despite the widespread use of essential oils, details about the exact mechanism of their antimicrobial action are yet to be explored. Thus, many researchers have recently attempted to identify the antimicrobial properties of essential oils. Clove oil has been widely investigated due to its popularity, availability, and high essential oil content (16).

Clove oil (Syzygium aromaticum) is widely used as a perfume and food flavoring (22), as a medicine for the treatment of asthma and various allergic disorders in Korea (12), and as a general antiseptic in medical dental practices (6). Ahmad et al. (2) evaluated antimicrobial activity of clove oil against a range of fungal pathogens including the ones for urogenital infection. Clove oil was found to possess strong antifungal activity against opportunistic fungal pathogens such as Candida albicans, Cryptococcus neoformans and Aspergillus fumigatus. The essential ingredient responsible for its antifungal activity is eugenol from the clove (15).

Eugenol is the main volatile compound of extracted oil from clove bud (S. aromaticum L.) that is used in traditional medicine, as a bactericide, fungicide (3, 4), anesthetic, and others (20). However, its antimicrobial activity was found to be higher against fungi than against bacteria (9). Besides eugenol (49-87\%), clove oil also contains $\beta$-caryophyllene (4-21\%), eugenyl acetate $(0.5-$ $21 \%$ ), smaller amounts of $\alpha$-humulene along with trace amounts $(<1 \%)$ of 25-35 other constituents (20).

The purpose of this study was to examine the antifungal activity of clove essential oil extracted from floral buds against dermatophytes, such as Trichophyton rubrum, Microsporum gypseum, and plant pathogenic fungi such as Fusarium moniliforme, Fusarium oxysporum, Aspergillus sp. and Mucor sp. The major constituent of the clove oil (eugenol) was also purified and analyzed in this study through chromatographic techniques. Also the effect of clove oil on fungal spores was studied.

\section{MATERIALS AND METHODS}

\section{Collection and identification of plant materials}

The dried flower buds of clove plant used in this study were purchased from local market of Bhopal, India. The buds were identified and authenticated by Dr. R.C. Rajak, Scientific Advisor, R\&D, Kilpest India Ltd., Bhopal, India.

\section{Extraction of volatile oil by steam distillation}

Clove buds (200 g) were powdered in a grinder and it was subjected to steam distillation, using the Clavenger apparatus (Pyrex), as described by Harbone (10). Distillation was done for 4 hours and the oil was drained off and dried over anhydrous sodium sulphate (4).

\section{Test organisms and preparation of inoculum}

Mucor sp. and Aspergillus sp. were isolated from soil samples; Microsporum gypseum and Trichophyton rubrum were obtained from Fungal Germplasm Culture Collection Center, Department of Biological Sciences, R.D. University, Jabalpur, India. Fusarium monoliforme NCIM 1100 was procured from NCIM, NCL, Pune, India and F. oxysporum MTCC 284 was procured from MTCC, IMTECH, Chandigarh, India. All the fungal cultures were maintained on Potato Dextrose Agar (PDA), Himedia, India, slant medium supplemented with $0.1 \%$ yeast extract and stored as active cultures at $4{ }^{\circ} \mathrm{C}$ for six months and revived thereafter. For the preparation of inoculum, all the test fungi were raised on Sabouraud Dextrose Agar (SDA), Himedia, by incubating the petriplates at $28 \pm 1{ }^{\circ} \mathrm{C}$ for 7 days in a BOD incubator. Fungal spore suspensions $(100 \mathrm{ml})$ were prepared in sterile distilled water containing $0.05 \%$ Tween-20.

\section{Screening of antifungal activity and determination of MIC}

Preliminary screening of antifungal activity of clove essential oil (EO) was done through agar well diffusion assay (17). Spore suspension of each isolate was prepared by taking a single fungal disc aseptically with a $5 \mathrm{~mm}$ cork borer from sporulating culture and mixed in $20 \mathrm{ml}$ sterile distilled water to which $50 \mu \mathrm{l}$ of Tween- 80 was added. The total number of spores was determined by counting under microscope using haemocytometer (Neubauer counting chamber). Fungal spore count was adjusted to $1 \times 10^{6}$ spores/ml by making appropriate dilutions (21). Petriplates containing SDA (Himedia) were inoculated aseptically with $500 \mu \mathrm{l}$ spore suspension through spread plate technique and kept in the 
laminar flow for $30 \mathrm{~min}$. Wells of $5 \mathrm{~mm}$ diameter were punched in the center of the petriplates by using sterile cork borer. Into each well, $10 \mu \mathrm{l}$ of the clove EO was dropped followed by $40 \mu \mathrm{l}$ of dimethyl sulphoxide (DMSO) so as to make the $50 \mu \mathrm{l}$ total volume in the well. Plates were kept in refrigerator at $4{ }^{\circ} \mathrm{C}$ for $3 \mathrm{~h}$, to allow EO and DMSO to diffuse into the agar medium. Plates were finally incubated at $28 \pm 1{ }^{\circ} \mathrm{C}$ for 5 days. Ketoconazol at the concentration of $1 \mathrm{mg}$ in $1 \mathrm{ml}$ of DMSO was used as positive control. DMSO without clove oil was set as negative control. The diameter of the zone of inhibition around each well was measured in $\mathrm{mm}$.

Minimum inhibitory concentration (MIC) was determined for all the fungal strains through agar dilution method. SDA plates were prepared with increasing concentration of clove EO from $1 \mu \mathrm{l} / \mathrm{ml}$ to $12 \mu \mathrm{l} / \mathrm{ml}(\mathrm{v} / \mathrm{v})$. Tween-20 (0.05\%) was used to dissolve EO in the medium. Plates were inoculated in the center with mycelial disc $(4 \mathrm{~mm})$ and incubated for 5 days followed by measurement of mean radial colony diameters. Three replicates were made for each treatment and medium with Tween-20 alone was set as control. The plate with lowest concentration of clove EO, showing no visible growth was regarded as the MIC (13).

\section{Separation of clove EO fractions through column chromatography}

Clove EO was subjected to column chromatography for fractionation based on increasing solvent polarity. Silica gel (60-120 mesh) slurry was made in petroleum ether $40-60{ }^{\circ} \mathrm{C}$ and poured into a glass column $(60 \times 3 \mathrm{~cm}$, ASGI, India) with sintered disc, to make an effective column of $45 \times 3 \mathrm{~cm}$ size. Analytical grade solvents of Qualigens, India were used. Ten milliliter of clove oil was loaded onto column bed and eluted first with $300 \mathrm{ml}$ petroleum ether followed by $300 \mathrm{ml}$ each of ether:chloroform (5:5), chloroform:ethyl acetate (3:2), chloroform:ethyl acetate (5:5), chloroform:ethyl acetate $(2: 8)$ and lastly with methanol. Column fractions were collected in pre weighed conical flasks $(500 \mathrm{ml})$ and were later concentrated by using rotary vacuum evaporator, buchi type
(Scientech, India) at $50{ }^{\circ} \mathrm{C}$ and finally weighed.

\section{Antifungal assay of column fractions}

Antifungal potential of all the six column fractions was determined through agar well diffusion assay. Fractions were equally diluted with $200 \mu \mathrm{l}$ ethanol in order to dissolve the crystallized fractions. Quantity used for bioassay was $5 \mu \mathrm{l}$ along with $45 \mu \mathrm{l}$ of DMSO, to make final volume of $50 \mu \mathrm{l}$. Eugenol (95\%) $5 \mu \mathrm{l}$ in $45 \mu \mathrm{l}$ DMSO (Oxford Chemicals, India) was used as positive control and DMSO $(50 \mu \mathrm{l})$ alone served as negative control.

\section{Analysis of column fractions through TLC}

Silica gel TLC was performed for analysis of column fractions along with eugenol standard. Silica plates of $1 \mathrm{~mm}$ thickness were prepared with silica gel H (Qualigens, India) by using TLC apparatus (Perfit India Ltd., India). Plates were activated in an oven (Tempo, India) for 2 hours at $65^{\circ} \mathrm{C}$. Six column fractions $5 \mu \mathrm{l}$ each were spotted with the help of Hamilton syringe (Germany) along with eugenol standard. Petroleum ether, toluene and ethyl acetate in a combination of 7:2:1 was used as developing solvent. When the solvent phase reached the top, the plate was air dried and exposed to iodine vapours in a glass chamber for $30 \mathrm{~min}$. The plate was then taken out and photographed (11).

\section{Analysis of clove EO through HPLC}

HPLC analysis of clove oil and laboratory reagent (LR) grade eugenol (Oxford Chemicals, India) was done in isocratic mode by using Shimadu's prominent HPLC system using a reverse phase C18 column [Phenomenex Luna, $5 \mu$ C18 (2) 100A $(250 \times 4.60 \mathrm{~mm})$ ], eluent: methanol/acetonitrile $(70: 30)$, UV detector: $254 \mathrm{~nm}$, flow rate $0.5 \mathrm{ml} / \mathrm{min}$, column temperature $40^{\circ} \mathrm{C}$. One hundred milligrams of EO was dissolved in $5 \mathrm{ml}$ of mobile phase solvent and $20 \mu \mathrm{l}$ was injected. The eugenol content was quantified based on the peak areas obtained in HPLC analysis taking all the peak areas together as $100 \%$. 


\section{Microscopic study of effect of clove EO and fraction II on} fungal mycelium and spores

Fifty microliters of clove EO and fraction II were put on the center of the glass slides. Fresh fungal mycelium piece bearing spores was taken out of petriplate with inoculating needle and immersed in the drop of clove oil on slides. After 1 $\mathrm{h}$ of incubation at ambient temperature, the slides were examined under light microscope and photographed.

\section{RESULTS AND DISCUSSION}

The results of the preliminary screening shown in Fig. 1 clearly indicate that clove essential oil (EO) is highly antifungal towards all tested fungal species. Considerable variation in inhibition zone sizes ranging from 12-22 $\mathrm{mm}$ was observed among fungal isolates depending on their sensitivity towards clove EO. The order of sensitivity in the descending array was Mucor sp. $>$ M. gypseum $>F$. monoliforme $>T$. rubrum $>$ Aspergillus sp. $>$ F. oxysporum. The positive control ketoconazole was very effective even at low concentration as it showed higher inhibition zones against all the fungal strains. No inhibition zones were observed with in negative control DMSO.

Lee et al. (13) elucidated the antifungal activities of eugenol and nerolidol isolated from Japanese cypress oil in a guinea pig model infected by $M$. gypseum. Their results suggest that eugenol and nerolidol could apply supplementary antifungal agents. Nunez et al. (14) demonstrated that the association of clove oleoresin with concentrated sugar has a strong fungicidal effect against $C$. albicans, $P$. citrinum, $A$. niger and T. mentagrophytes. Ahmad et al. (2) reported clove oil to possess strong antifungal activity against $C$. albicans, $C$. neoformans and A. fumigatus.

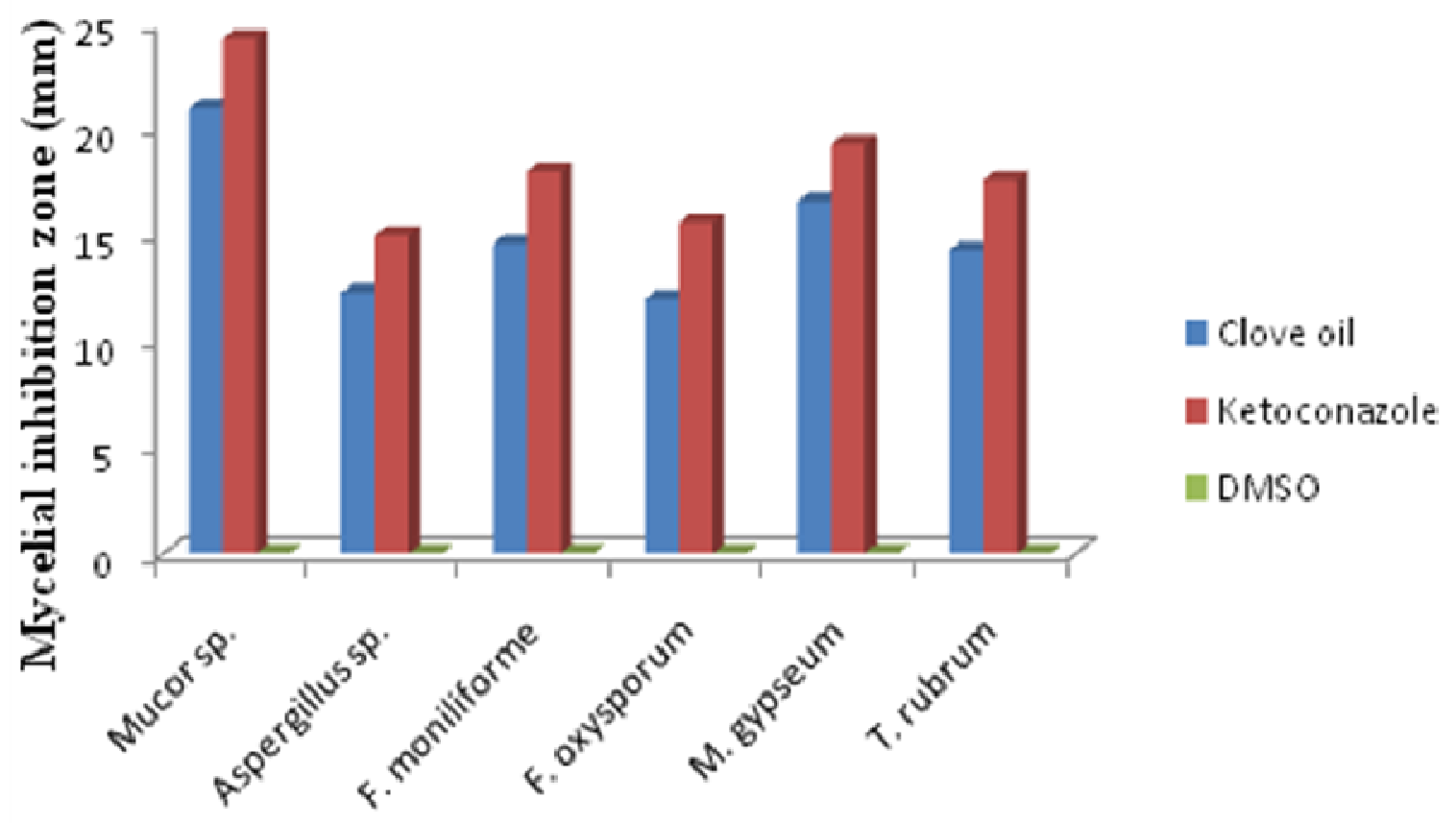

Figure 1. Mycelial inhibition (mm) of various fungal strains with clove EO (10 $\mu \mathrm{l})$, Ketoconazole $(1 \mathrm{mg} / \mathrm{ml})$ and DMSO $(10 \mu \mathrm{l})$ 
MIC of clove EO for the tested fungal strains was found to be from 9-12 $\mu \mathrm{l} / \mathrm{ml}$ (Table 1). Mucor sp., M. gypseum and T. rubrum were inhibited at $9 \mu \mathrm{l} / \mathrm{ml}$ of clove oil followed by Aspergillus sp. and $F$. oxysporum at $10 \mu \mathrm{l} / \mathrm{ml}$ and $F$. monoliforme at $12 \mu \mathrm{l} / \mathrm{ml}$. Mycelial inhibition was concentration dependent as the colonies diameters were decreased with increasing quantity of EO. Except for Mucor and Aspergillus all other fungal strains exhibited considerable inhibition even at
$1 \mu \mathrm{l} / \mathrm{ml}$ concentration.

Pinto et al. (18) studied the antifungal activity of clove essential oil, obtained from S. aromaticum. They determined MIC to evaluate the antifungal activity of the clove oil and its main component, eugenol, against Candida, Aspergillus, and dermatophyte clinical and ATCC (American Type Culture Collection) strains. The essential oil and eugenol showed inhibitory activity against all the tested strains.

Table 1. MIC of clove oil against fungal strains after 5 days of incubation

\begin{tabular}{|c|c|c|c|c|c|c|c|c|c|}
\hline \multirow{3}{*}{ Fungal strain } & \multicolumn{9}{|c|}{ Mycelial diameter (mm) } \\
\hline & \multirow[t]{2}{*}{$\begin{array}{l}\text { Negative } \\
\text { Control } \\
\end{array}$} & & \multicolumn{7}{|c|}{ Different conc. of clove oil $(\mu \mathrm{l} / \mathrm{ml})$ in medium } \\
\hline & & 1 & 2 & 4 & 8 & 9 & 10 & 11 & 12 \\
\hline Mucor sp. & 100 & 100 & 100 & $32 \pm 0.8$ & $21 \pm 0.8$ & - & - & - & - \\
\hline Aspergillus sp. & 100 & 100 & 100 & $31.3 \pm 0.9$ & $20.6 \pm 0.4$ & $3.3 \pm 0.4$ & - & - & - \\
\hline F. moniliforme & 100 & $31.3 \pm 0.4$ & $10 \pm 0.8$ & $8.6 \pm 0.4$ & $7.6 \pm 0.9$ & $6.3 \pm 0.4$ & $5.6 \pm 0.4$ & $2.6 \pm 0.4$ & - \\
\hline F. oxysporum & $67.3 \pm 1.7$ & $27.6 \pm 0.4$ & $9.6 \pm 0.4$ & $8.3 \pm 0.4$ & $7.3 \pm 0.4$ & $3.3 \pm 0.4$ & - & - & - \\
\hline $\begin{array}{l}\text { Microsporum } \\
\text { gypseum. }\end{array}$ & $19.3 \pm 0.9$ & $4.6 \pm 0.4$ & $4.3 \pm 0.4$ & $3.6 \pm 0.4$ & $3.3 \pm 0.9$ & - & - & - & - \\
\hline $\begin{array}{l}\text { Trichophyton } \\
\text { rubrum }\end{array}$ & $27.6 \pm 0.4$ & $11 \pm 0.8$ & $8 \pm 0.8$ & $5.6 \pm 0.4$ & $3.6 \pm 0.9$ & - & - & - & - \\
\hline
\end{tabular}

Figures are Mean $\pm \mathrm{SD}$

'-' indicates absence of any visible growth

Table 2 shows that among the column eluents, highest quantity of $5.49 \mathrm{~g}$ was obtained in ethereal fraction followed by ether:chloroform (5:5) and chloroform:ethyl acetate (3:2). All other eluted components were in meager quantity. Non polar fractions were oily and light colored while polar fractions were solids and dark colored. The result of antifungal assay shown in Table 3 indicates that column fraction II \& III possess antifungal components, especially fraction II exhibited higher degree of inhibition, comparable to that of eugenol standard. This gave an indication that column fraction II may contain substantial amount of eugenol. It is also possible that some minor compounds present in fraction II may have promoted the inhibitory potential to some extent. In rest of the fractions no inhibition was observed.

Table 2. Quantity, consistency and color of six column fractions and clove

\begin{tabular}{lcc}
\hline Column Fractions eluted with following solvent & $\begin{array}{c}\text { Weight of } \\
\text { samples (g) }\end{array}$ & $\begin{array}{c}\text { Consistency/ } \\
\text { color }\end{array}$ \\
\hline Ether - I & 5.49 & Light colorless Oil \\
Ether: Chloroform (5:5) - II & 2.22 & Viscous yellow oil \\
Chloroform: Ethyl acetate (3:2) - III & 0.58 & Semisolid yellow \\
Chloroform: Ethyl acetate (5:5) - IV & 0.03 & Brown solid \\
Chloroform: Ethyl acetate (2:8) - V & 0.08 & Brown solid \\
Methanol - VI & 0.05 & Dark brown solid \\
\hline
\end{tabular}


Table 3. Antifungal assay of six column fractions

\begin{tabular}{|c|c|c|c|c|c|c|c|}
\hline \multirow{2}{*}{ Fungal species } & \multicolumn{6}{|c|}{ Mycelial zone inhibition diameter $(\mathrm{mm})$ in following column fractions $(5 \mu \mathrm{l})$} & \multirow{2}{*}{$\begin{array}{c}\text { Inhibition zone } \\
\text { in eugenol } 95 \%(5 \mu \mathrm{l})\end{array}$} \\
\hline & I & II & III & IV & $\mathbf{V}$ & VI & \\
\hline Mucorsp. & - & 20.3 & 3 & - & - & - & 22.6 \\
\hline F. moniliforme & - & 15 & 4 & - & - & - & 15 \\
\hline F. oxysporum & - & 13.3 & 3 & - & - & - & 14.6 \\
\hline Microsporum gypseum & - & 18 & 4.3 & - & - & - & 21.3 \\
\hline
\end{tabular}

-' indicates absence of any visible zone

TLC results of column fractions (Lanes 1-6) along with eugenol standard (Lane 7) are shown in Fig. 2. Upon exposure of TLC plate to iodine vapors the result clearly shows presence of high quantity of eugenol in column fraction II. Small quantity of eugenol was also present in fraction III as a result of which little inhibition zones were also observed in this fraction. The non polar oily compounds in fraction I moved faster with developing solvent close to the solvent front. The highly polar compounds in fraction $\mathrm{V}$ travelled only few centimeters, and that of fraction VI didn't moved at all on TLC plate. The $\mathrm{R}_{\mathrm{f}}$ value calculated for column fraction II at lane 2 and for eugenol standard was $0.85 \mathrm{~cm}$. The result of antifungal assay of column fractions and that of TLC proves that the antifungal activity of the clove oil is due to its high eugenol content.

Park et al. (16) found similar results in relation to clove EO. They performed TLC and column chromatography assay to identify the active antifungal components and their fractionation. They concluded that eugenol was the most effective antifungal constituent of clove oil against the dermatophytes $T$. mentagrophytes and M. canis.

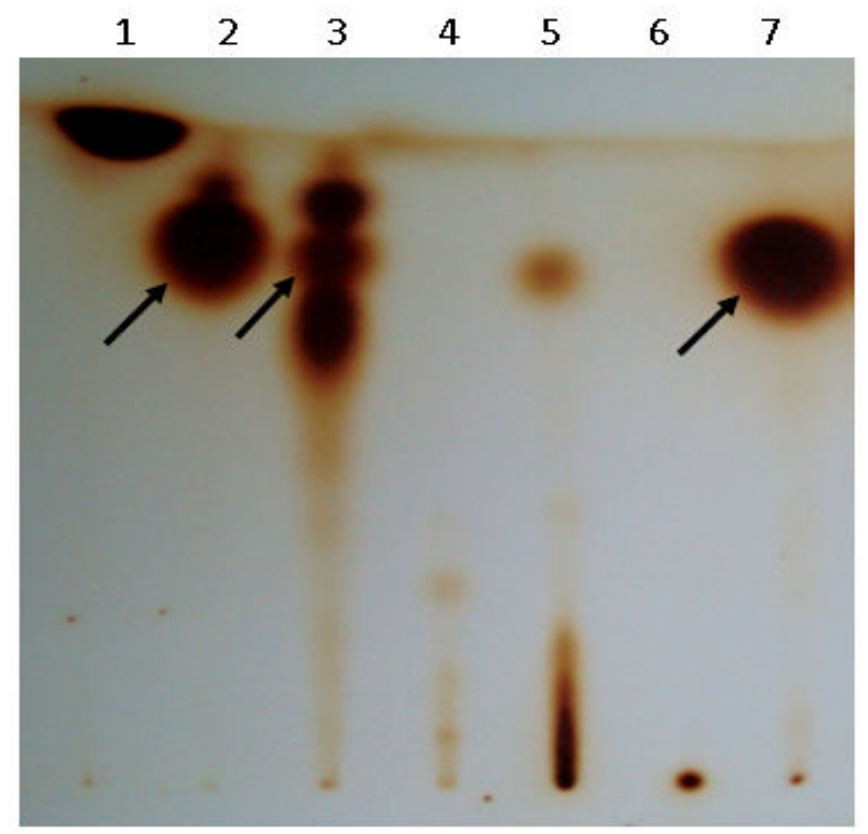

Figure 2. TLC plate showing column fractions (I, II, III, IV, V, VI) respectively in lane 1, 2, 3, 4, 5, 6. Lane 2 (column fraction II) showed presence of substantial amount of eugenol when compared with standard eugenol spot $(5 \mu l)$ at lane 7 . 
HPLC analyses of eugenol (LR grade) and clove oil are shown in Fig. 3A and 3B respectively. Peak areas of graphs depicted percentage of eugenol to be $90.55 \%$ represented by retention time $3.056 \mathrm{~min}$. Clove oil, when compared with eugenol, similar peak at a retention time of 3.045 min was observed which is $68.73 \%$. Since, the principal component in clove oil is eugenol therefore; its strong antifungal activity may be attributed to eugenol.

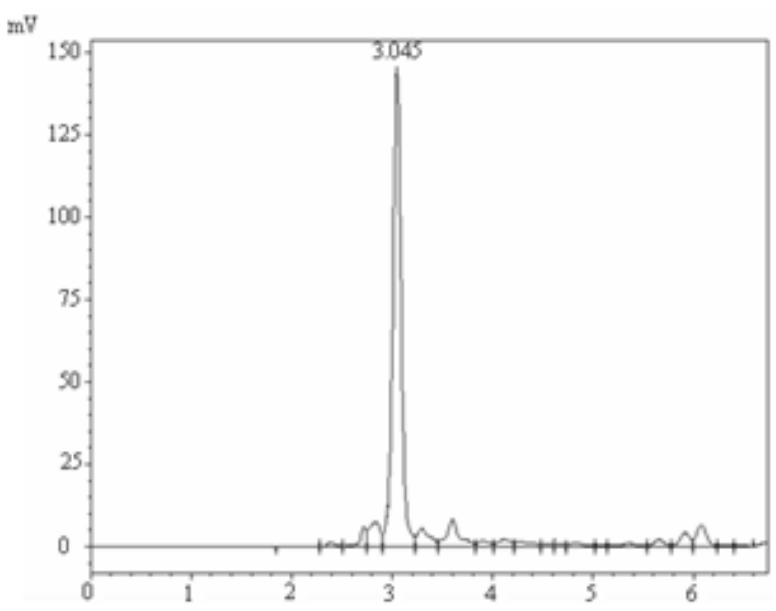

Fig. 3B

Fig. 3A

Figure 3. A: HPLC elution profile of eugenol (95\% LR grade) with retention time of 3.056 min confirmed $90.55 \%$ eugenol. B: HPLC elution profile of clove oil confirmed presence of $68.73 \%$ eugenol with retention time of $3.045 \mathrm{~min}$

Some authors have done HPLC for purification and analysis of essential oils. Benincasa (5) analyzed essential oils such as citrus by HPLC with standard columns in reversed and normal phase. Volatile and non-volatile fractions were investigated, and in the non-volatile fraction some coumarins were identified. Rauber et al. (19) developed a HPLC method for determination of citral in volatile oil of Cymbopogon citratus.

Pinto et al. (18) analyzed clove oil obtained commercially by gas chromatography and by gas-chromatography-mass spectroscopy. The essential oil showed high contents of eugenol (85.3 \%). Ayoola et al. (4) has explained gas chromatography-mass spectrometry (GC-MS) analysis of the clove oil revealing that the components were eugenol, caryophyllene, eugenol acetate and alpha-humelene, with eugenol being the main component. Cheng et al. (8) revealed in antifungal tests that cinnamaldehyde, $\alpha$-methyl cinnamaldehyde, (E)-2-methylcinnamic acid, eugenol and isoeugenol exhibited strong antifungal activity against all fungi tested. Chami et al. (7) evaluated carvacrol and eugenol, the main (phenolic) components of essential oils of some aromatic plants for their therapeutic efficacy in the treatment of experimental oral candidiasis induced by Candida albicans in immunosuppressed rats. They claimed that, carvacrol and eugenol could be considered as strong antifungal agents and could be proposed as therapeutic agents for oral candidiasis.

After $1 \mathrm{hr}$ of treatment of fungal mycelia bearing spores and conidia with clove oil, lysis and distortion of spores was observed in all the fungal isolates. The effect was profound and clearly visible in form of deformities/distortion of spore structure. In case of $M$. gypseum spores, leakage at multiple sites with balloon like swellings was observed (Fig. 4B and 5B). Similar effects were noted when spores were treated with standard eugenol. 


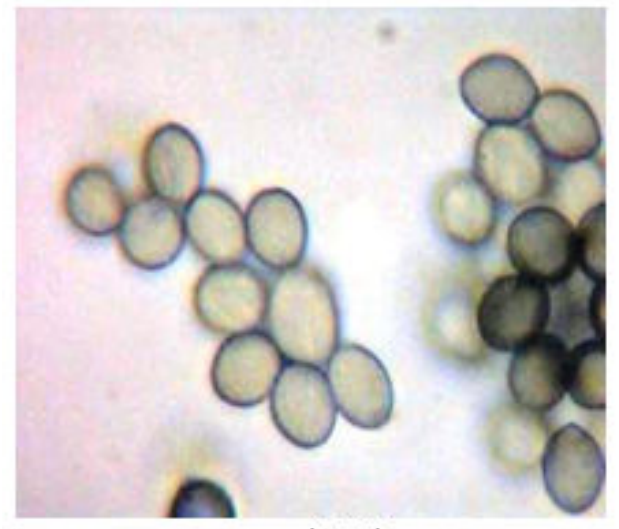

(4A)

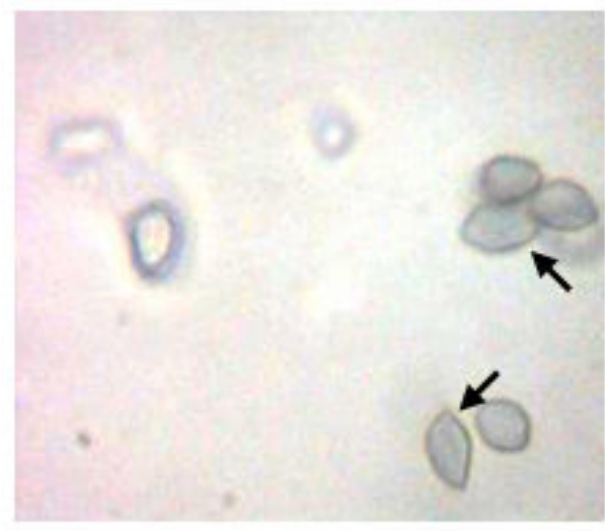

(4B)

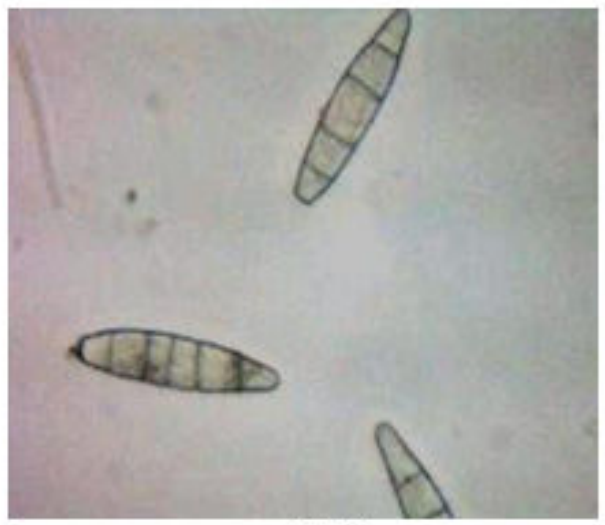

(5A)

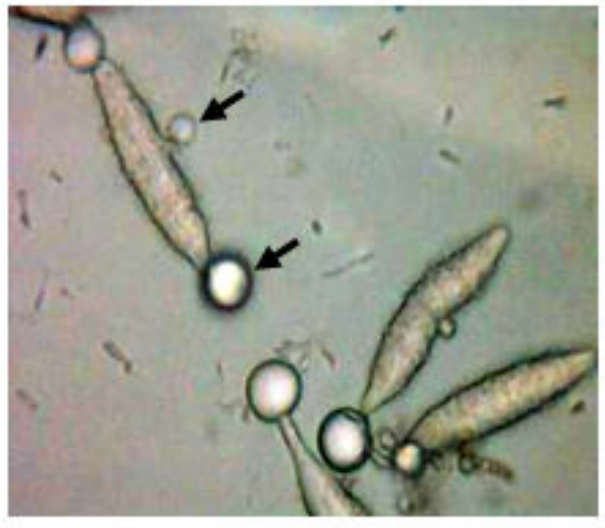

(5B)

Figure 4. A: Showing Mucor sp. spores of control. 4B Showing deformities/ distortion of spores of Mucor sp. upon treatment with column fraction II. Fig. 5A: Showing M. gypseum spores of control. 5B Showing leakage of cellular components of spores of $M$. gypseum at tips and near center upon treatment with column fraction II

Park et al. (16) studied effect of clove oil on Trichophyton mentagrophytes with the help of transmission electron microscope. They observed the expansion of its endoplasmic reticulum near the cell membranes of a hyphal specimen treated with eugenol. In addition, the inner mitochondrial membranes were partially destroyed, with complete destruction of the cell wall. According to their results, they concluded that the antifungal activity of eugenol toward T. mentagrophytes is due to changes in fungal cell structure at the membrane level.

It is concluded, that the essential oil of $S$. aromaticum was active against all the tested fungal strains with low MIC values. Purification of active ingredient eugenol can be accomplished through column chromatography. Analysis of column purified fractions through TLC and GC showed presence of major quantity of eugenol in fraction II. Microscopic study clearly indicated lytic effect of clove oil and column fraction II on fungal mycelium and spores. Hence the anti-fungal property demonstrated by the clove EO is attributed to the eugenol.

\section{ACKNOWLEDGEMENTS}

Authors are grateful to Mr. Dhirendra Dubey, Director, Kilpest India Limited for providing funds and lab facility for this research work. 


\section{REFERENCES}

1. Abad, M.J.; Ansuategui, M.; Bermejo, P. (2007). Active antifungal substances from natural sources. Arkivoc., 7, 116-145.

2. Ahmad, N.; Alam, M.K.; Shehbaz, A.; Khan, A.; Mannan, A.; Rashid, H.S.; Bisht, B.; Owais, M. (2005). Antimicrobial activity of clove oil and its potential in the treatment of vaginal candidiasis. J. Drug Targeting. $13,555-561$.

3. Arras, G.; Usai, M. (2001). Fungitoxic activity of essential oils against four post-harvest citrus pathogens: Chemical analysis of Thymus capitates oil and its effect in sub-atmospheric pressure conditions. J. Food Prot. 64, 1025-1029.

4. Ayoola, G.A.; Lawore, F.M.; Adelowotan, T.; Aibinu, I.E.; Adenipekun, E.; Coker, H.A.B.; Odugbemi, T.O. (2008). Chemical analysis and antimicrobial activity of the essential oil of Syzigium aromaticum (clove). African J. Microbiol. Res. 2, 162-166.

5. Benincasa, M.; Buiarelli F.; Cartoni, G.P.; Coccioli, F. (1990). Analysis of lemon and bergamot essential oils by HPLC with microbore columns. Chromatographia. 30, 271-276.

6. Cai, L.; Wu, C.D. (1996). Compounds from Syzygium aromaticum processing growth inhibitory activity against oral pathogens. J. Nat. Prod. 59, 987-990.

7. Chami, N.; Chami, F.; Bennis, S.; Trouillas, J.; Remmal, A. (2004). Antifungal treatment with carvacrol and eugenol of oral candidiasis in immunosuppressed rats. Braz. J. Infect. Dis. 8, 217-226.

8. Cheng, S.S.; Liu, J.Y.; Chang, E.H.; Chang, S.T. (2008). Antifungal activity of cinnamaldehyde and eugenol congeners against wood-rot fungi. Bioresource Technol. 99, 5145-5149.

9. Hammer, K.A.; Carson, C.F.; Riley, T.V. (1999). Antimicrobial activity of essential oils and other plant extracts. J. Appl. Microbiol. 86, 985-990.

10. Harbone, J.B. (1998). Essential oils. In: Phytochemical Methods: A guide to modern techniques in plant analysis, 3rd ed. Chapman and Hall, PA,USA. pp. 110-124.

11. Hostettmann, K. (1999). Strategy for the biological evaluation of plant extracts. Pure App. Chem. 70, 1109-1113.

12. Kim, H.M.; Lee, E.H.; Hong, S.H.; Song, H.J.; Shin, M.K.; Kim, S.H.;
Shin, T.Y. (1998). Effect of Syzygium aromaticum extract on immediate hypersensitivity in rat. J. Ethnopharmacol. 60, 125-131.

13. Lee, S.J.; Han, J.I.; Lee, G.S.; Park, M.J.; Choi, I.G.; Na, K.J.; Jeung, E.B. (2007). Antifungal effect of eugenol and nerolidol against Microsporum gypseum in a guinea pig model. Biol. Pharm. Bull. 30, 184-188.

14. Nunez, L.; D’Aquino, M.; Chirife, J. (2001). Antifungal properties of clove oil (Eugenia caryophylata) in sugar solution. Brazilian J. Microbiol. 32,123-126.

15. Panizzi, L.; Falmini, G.; Cioni, P.L.; Morelli, I. (1993). Composition and antimicrobial properties of essential oil of four Mediterranean Lamiaceae. J. Ethnopharm. 39, 167-170.

16. Park, M.J.; Gwak, K.S.; Yang, I.; Choi, W.S.; Jo, H.J.; Chang, J.W.; Jeung, E.B.; Choi, I.G. (2007). Antifungal activities of the essential oils in Syzygium aromaticum (L.) Merr. Et Perry and Leptospermum petersonii Bailey and their constituents against various dermatophytes. The J. Microbiol., 45, 460-465.

17. Perez, C.; Paul, M.; Bazerque, P. (1990). Antibiotic assay by agar - well diffusion method. Acta. Bio. Med. Exp. 15, 113 - 115.

18. Pinto, E.; Vale-Silva, L.; Cavaleiro, C.; Salgueiro, L. (2009). Antifungal activity of the clove essential oil from Syzygium aromaticum (Eugenia caryophyllus) on Candida, Aspergillus and dermatophyte species. J. Med. Microbiol. 58, 1454-62.

19. Rauber, C.S.; Guterres, S.S.; Schapoval, E.E.S. (2005). LC determination of citral in Cymbopogon citratus volatile oil. J. Pharma. Biomed. Anal. 37, 597-601.

20. Santos, A.L.; Chierice, G.O.; Alexander, K.S.; Riga, A.; Matthews, E. (2009). Characterization of the raw essential oil eugenol extracted from Syzygium aromaticum L. J. Therm. Anal. Calorim. 96, 821-825.

21. Yalemtesfa, B.; Alemu, T.; Santhanam, A. (2010). Solid substrate fermentation and conversion of orange waste in to fungal biomass using Aspergillus niger KA-06 and Chaetomium Spp KC-06. African J. Microbiol. Res. 4, 1275-1281.

22. Zheng, G.Q.; Kenney, P.M.; Lam, L.K. (1992). Sesquiterpenes from clove Eugenia caryophyllata) as potential anticarcinogenic agents. J. Nat. Prod. 55, 999-1003. 